MATEC Web of Conferences 22,01052 (2015)

DOI: $10.1051 /$ matec conf/ 20152201052

(C) Owned by the authors, published by EDP Sciences, 2015

\title{
Impact of Different Carbon Policies on City Logistics Network
}

\author{
Jianhua Yang \& Huijie Gao* \\ Donlinks School of Economic and Management, University of Science and Technology Beijing, Beijing, China
}

\begin{abstract}
A programming model for a four-layer urban logistics distribution network is constructed and revised based on three types of carbon emissions policies such as Carbon tax, carbon emissions Cap, Carbon Trade. Effects of different policies on logistics costs and carbon emissions are analyzed based on a spatial Logistics Infrastructure layout of Beijing. Research findings are as follows: First, based on low-carbon policies, the logistics costs and carbon emissions can be changed by different modes of transport in a certain extent; second, only when carbon taxes and carbon trading prices are higher, carbon taxes and carbon trading policies can reduce carbon emissions while not significantly increase logistics costs at the same time, and more effectively achieve carbon reduction targets than use carbon cap policy.
\end{abstract}

Keywords: low-carbon policy; city logistics; carbon emissions

\section{INTRODUCTION}

There is a long-term debate about urban logistics because it involves environmental pollution, traffic jams and traffic accidents which are three most prominent problems in city. The most difficult problem to be solved is environmental pollution. Recent empirical studies estimate that urban freight vehicles account for 6 to $18 \%$ of total urban travel (Figliozzi, M.A., 2010) and $21 \%$ of $\mathrm{CO}_{2}$ emissions(Schoemaker, Allen, Huschebek \& Monigl, 2006). Governments are under growing pressure to enact legislation to curb the amount of these emissions, such as carbon tax, emission cap, carbon trade and so on. In order to predict the effectiveness of a carbon policy and to decide the right parameters for the policy, it is important to understand the response of freight shippers towards carbon policies. A carbon policy's impacts on a company may include design of its logistics network, different choices of transportation modes, and better logistics management (Mingzhou Jin et al, 2013).

This paper will investigate the impact of the three most common carbon policies on the city logistics distribution, and it also includes the design of the city logistics network. Optimization models are proposed for the decision making of the city logistics based on various carbon policies

The remainder of this paper is organized as follows. Section 2 states a literature review. Section 3 provides the urban logistics network structure and the optimization formulations of designing the logistics network for a retailer based on various carbonpolicies.Section 4 presents an empirical study and discusses the impact of different types of carbon emission.Section5is written to be ended with conclusions and provides future research directions.

*Corresponding author: gaohuijie2008@163.com

\section{LITERATURE REVIEW}

The literature review for this paper covers two main areas of research: the research on city logistics network design and the study of carbon policies. City logistics distribution is mainly refers to the logistics activities in the city. The ideal mode is used in most of the goods transported into the logistics park first, then dispatched to the logistics center according to the logistics information, and transferred to the distribution center through the centralized storage, finally distributed to retailers by the distribution center.

There are several studies focusing on the impact of carbon policies on the logistics distribution. Ming Zhou Jin et al.(2013)studied the impact of carbon policies on the supply chain design and logistics of a major retailer, they showed that different policies have different impacts on the costs and the effectiveness of emission reduction. Hoen et al.(2014) proposed optimization models including the transportation costs and the emission costs, studied the results for different types of emission regulation, and found that even though large emission reductions can be obtained by switching to a different transport mode, the actual decision depends on the regulation and non-monetary considerations. Benjaafar et al. (2013) designed optimization models for supply chain operational decision making based on several carbon policies: strict carbon caps, carbon tax, carbon cap-and-trade, and carbon off sets. Roumboutsos et al (2014) introduces a methodology based on the Systems of Innovation approach to examine the process by which electric vehicles may be introduced in city logistics. Yang et a 1 (2014) developed a model with the minimum operational cost as the goal in which carbon tax cost was also integrated, and a bi-level city logistics distribution network was formulated with some high carbon-efficient facilities to be allocated onto various distribution centers. Guy

This is an Open Access article distributed under the terms of the Creative Commons Attribution License 4.0, which permits unrestricted use, distribution, and reproduction in any medium, provided the original work is properly cited. 
et al (2014) analyzed Telematics, urban freight logistics and low carbon road networks. Their findings showed that the topology of urban street patterns strongly interacts with the level of telematics and the route guidance. Diabat and Simichi-Levi (2010) formulated a mixed-integer program for a company to design their optimal supply chain network while meeting their carbon cap. Their model focused on the impact of one carbon policy and did not consider transport vehicle type choice. In this paper, we design a four-layer urban logistics distribution network and introduce programming models based on three carbon policies: carbon tax, carbon emissions cap and carbon trade.

\section{OPTIMIZATION MODELS UNDER VARIOUS CARBON POLICIES}

The urban logistics distribution network is formed by four layers: a set of logistics bases (LBs), a set of logistics centers (LCs), a set of distribution centers (DCs), and a set of a set of retailers, illustrated inFigure1.The problem is to study how the specific carbon policies would affect the costs and emissions of various firms.

We make some assumptions as follows:

(1) The position and capability of LBs, LCs, DCs and the demanded quantity of retailers are known. The position is permanently fixed for a long time.

(2) The goal of urban logistics distribution is minimum distribution cost integrated with carbon emission cost.

(3) Distribution costs and the amount of carbon emissions are linearly proportional to the distance and volume. They are only based on the traveled distance between facilities.

To formulate the problem, the following notations are used:

$I$ is the number of logistics bases, indexed by $i$;

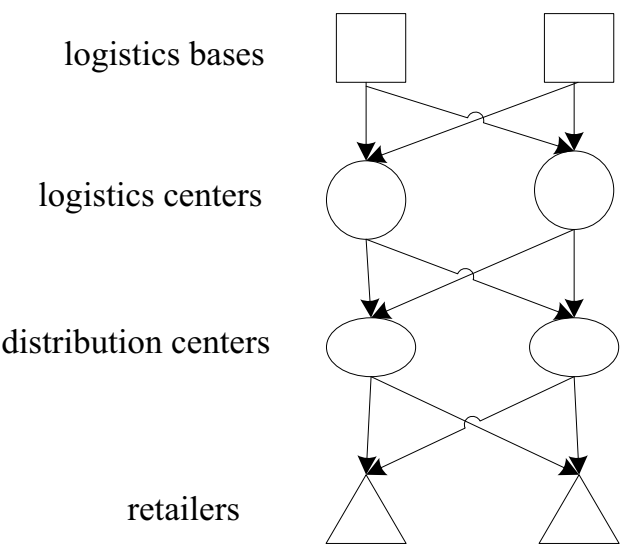

Figure 1. Structure of urban logistics distribution network
$J$ is the number of logistics centers, which is indexed by $j$;

$k$

$K$ is the number of distribution centers, indexed by

$M$ is the number of retailers, which is indexed by $m$; $A_{i}$ is the capacity of logistics bases;

$B$ is the capacity of logistics centers;

$C_{k}$ is the capacity of distribution centers;

$N$ is the set of vehicle type.

$x_{i j}^{n}$ is the amount in tons shipped from logistics base $I$ to logistics center $j$ with vehicle type $n$.

$b_{i j}^{n}$ is the cost of shipping one ton from logistics baseito logistics center $j$ per kilometer with vehicle type $n$.

$y_{j k}^{n}$ is the amount in tons shipped from logistics center $j$ to distribution center $k$ with vehicle type $n$.

$b_{j k}^{n}$ is the cost of shipping one ton from logistics center $j$ to distribution center $k$ per kilometer with vehicle type $n$.

$z^{n}$ is the amount in tons shipped from distribution center $k$ to retailer $m$ with vehicle type $n$.

$c_{l n}^{n}$ is the cost of shipping one ton from distribution center $k$ to retailer $m$ per kilometer with vehicle type $n$. $d_{m}$ is the daily demand in tonnage at retailer $m$;

$e_{i j}^{n}$ is the carbon emission in kilograms (kg) of shipping one ton from logistics base $I$ to logistics center $j$ with vehicle type $n$.

$e_{j k}^{n}$ is the carbon emission in kilograms $(\mathrm{kg})$ of shipping one ton from logistics center $j$ to distribution center $k$ with vehicle type $n$.

$e_{k m}^{n}$ is the carbon emission in kilograms $(\mathrm{kg})$ of shipping one ton from distribution center $k$ to retailer $m$ with the vehicle type $n$.

$l$ is the distance from logistics base $I$ to logistics center $j$;

$l_{j k}$ is the distance from logistics center $j$ to distribution center $k$;

$l_{k m}$ is the distance from distribution center $k$ to retailer $m$.

\subsection{Basic model}

In the following models, there is no carbon policy so that the retailer considers logistics cost and carbon emissions in the transportation.

Model I:

$$
\begin{aligned}
& \min \sum_{i=1}^{I} \sum_{n=1}^{N} \sum_{j=1}^{J} x_{i j}^{n} a_{i j}^{n} l_{i j}+\sum_{n=1}^{N} \sum_{j=1}^{J} \sum_{k=1}^{K} y_{j k}^{n} b_{j k}^{n} l_{j k} \\
& +\sum_{n=1}^{N} \sum_{k=1}^{K} \sum_{m=1}^{M} z_{k m}^{n} c_{k m}^{n} l_{k m} \\
& \min \sum_{n=1}^{N} \sum_{i=1}^{I} \sum_{j=1}^{J} x_{i j}^{n} e_{i j}^{n} l_{i j}+\sum_{n=1}^{N} \sum_{j=1}^{J} \sum_{k=1}^{K} y_{j k}^{n} e_{j k}^{n} l_{j k} \\
& +\sum_{n=1}^{N} \sum_{k=1}^{K} \sum_{m=1}^{M} z_{k m}^{n} e_{k m}^{n} l_{k m}
\end{aligned}
$$




$$
\begin{aligned}
& \sum_{k=1}^{K} \sum_{n=1}^{N} z_{k m}^{n}=d_{m} \\
& \sum_{j=1}^{J} \sum_{n=1}^{N} x_{i j}^{n} \leq A_{i} \\
& \sum_{k=1}^{K} \sum_{n=1}^{N} y_{j k}^{n} \leq B_{j} \\
& \sum_{m=1}^{M} \sum_{n=1}^{N} z_{k m}^{n} \leq C_{k} \\
& \sum_{j=1}^{J} \sum_{n=1}^{N} x_{i j}^{n}=\sum_{k=1}^{K} \sum_{n=1}^{N} y_{j k}^{n}=\sum_{m=1}^{M} \sum_{n=1}^{N} z_{k m}^{n} \\
& x_{i j}^{n}, y_{j k}^{n}, z_{k m}^{n} \geq 0
\end{aligned}
$$

The objective function equation (1) minimizes the sum of the distribution costs. Equation (2) minimizes the carbon emissions. Constraint set (3) ensures that the demand of each retailer is satisfied. Constraint sets (4)-(6) represent the capacity restriction of every layer. Constraint set (7) keeps the flow conservation at every layer.

\subsection{A model under carbon tax}

A carbon tax is an effective means of reducing carbon emissions, which is considered as the tax on $\mathrm{CO}_{2}$ emissions. Let us suppose that a carbon tax is with the rate of $t$ dollars per $\mathrm{kg}$ of $\mathrm{CO}_{2}$, we modify the objective function (1) and (2) into (9) as follows:

$$
\begin{gathered}
\text { Model II: } \\
\min \sum_{i}^{I} \sum_{j}^{J} \sum_{n}^{N} x_{i j}^{n} a_{i j}^{n} l_{i j}+\sum_{j}^{J} \sum_{k}^{K} \sum_{n}^{N} y^{\prime} \\
+\sum_{i}^{I} \sum_{j}^{J} \sum_{n}^{N} t x_{i j}^{n} l_{i j}^{n} l_{i j}+\sum_{j}^{J} \sum_{k}^{K} \sum_{n}^{N} t y_{j k}^{n} e^{n} \\
=\sum_{i}^{I} \sum_{j}^{J} \sum_{n}^{N} x_{i j}^{n} n_{i j}^{n} l_{i j}+\sum_{j}^{J} \sum_{k}^{K} \sum_{n}^{N} y_{j k}^{n} u^{n} \\
\text { Where, } u_{i j}^{n}=a_{i j}^{n}+t e_{i j}^{n}, \\
u_{j k}^{n}=b_{j k}^{n}+t e_{j k}^{n}, \\
u_{k m}^{n}=c_{k m}^{n}+t e_{k m}^{n} .
\end{gathered}
$$$$
\min \sum_{i}^{I} \sum_{j}^{J} \sum_{n}^{N} x_{i j}^{n} a_{i j}^{n} l_{i j}+\sum_{j}^{J} \sum_{k}^{K} \sum_{n}^{N} y_{j k}^{n} b_{j k}^{n} l_{j k}+\sum_{k}^{K} \sum_{m}^{M} \sum_{n}^{N} z_{k m}^{n} c_{k m}^{n} l_{k m}
$$$$
+\sum_{i}^{I} \sum_{j}^{J} \sum_{n}^{N} t x_{i j}^{n} e_{i j}^{n} l_{i j}+\sum_{j}^{J} \sum_{k}^{K} \sum_{n}^{N} t y_{j k}^{n} e_{j k}^{n} l_{j k}+\sum_{k}^{K} \sum_{m}^{M} \sum_{n}^{N} t z_{k m}^{n} e_{k m}^{n} l_{k m}
$$$$
=\sum_{i}^{I} \sum_{j}^{J} \sum_{n}^{N} x_{i j}^{n} u_{i j}^{n} l_{i j}+\sum_{j}^{J} \sum_{k}^{K} \sum_{n}^{N} y_{j k}^{n} u_{j k}^{n} l_{j k}+\sum_{k}^{K} \sum_{m}^{M} \sum_{n}^{N} z_{k n n}^{n} u_{k m}^{n} l_{k m n}
$$

The objective function (9) is together with constraint sets (3)-(8).The objective function equation (9) minimizes the model when a carbon tax is charged. Carbon Tax Model is similar to Model I except considering carbon emission costs.

\subsection{Model of under carbon cap}

A carbon cap is another popular means of controlling emissions. $\mathrm{E}$ (in $\mathrm{kg}$ ) is the carbon cap of the retailer.
Carbon Cap Model is shown as follows:

Model III:

$\min \sum_{i}^{I} \sum_{j}^{J} \sum_{n}^{N} x_{i j}^{n} a_{i j}^{n} l_{i j}+\sum_{j}^{J} \sum_{k}^{K} \sum_{n}^{N} y_{j k}^{n} b_{j k}^{n} l_{j k}$

$+\sum_{k}^{K} \sum_{m}^{M} \sum_{n}^{N} z_{k m}^{n} c_{k m}^{n} l_{k m}$

$$
\begin{aligned}
& \sum_{i}^{I} \sum_{j}^{J} \sum_{n}^{N} x_{i j}^{n} e_{i j}^{n} l_{i j}+\sum_{j}^{J} \sum_{k}^{K} \sum_{n}^{N} y_{j k}^{n} e_{j k}^{n} l_{j k} \\
& +\sum_{k}^{K} \sum_{m}^{M} \sum_{n}^{N} z_{k m}^{n} e_{k m}^{n} l_{k m} \leq E
\end{aligned}
$$

The Carbon Cap Model is a minimum network cost problem with constraint sets (3)-(8). Constraint (11) is carbon emissions in the transport process. Logistics activities should be carried out within the prescribed limit carbon emissions.

\subsection{A model under carbon trade}

Carbon Trade is a market mechanism for various industries. They will be included as follows:

A carbon trade market can meet the carbon cap by selling or buying carbon quote. $b^{+}\left(b^{-}\right)$is the amount of carbon $(\mathrm{kg})$ sold (or bought) in a carbon trade market. $p$ is the carbon selling (buying) price per $\mathrm{kg}$ in the carbon market. The objective function of the Carbon Market Model becomes (12).

Model IV:

$$
\begin{aligned}
& \min \sum_{i}^{I} \sum_{j}^{J} \sum_{n}^{N} x_{i j}^{n} a_{i j}^{n} l_{i j}+\sum_{j}^{J} \sum_{k}^{K} \sum_{n}^{N} y_{j k}^{n} b_{j k}^{n} l_{j k} \\
& +\sum_{k}^{K} \sum_{m}^{M} \sum_{n}^{N} z_{k m}^{n} c_{k m}^{n} l_{k m}-p b^{+}+p b^{-} \\
& \sum_{i}^{I} \sum_{j}^{J} \sum_{n}^{N} x_{i j}^{n} e_{i j}^{n} l_{i j}+\sum_{j}^{J} \sum_{k}^{K} \sum_{n}^{N} y_{j k}^{n} e_{j k}^{n} l_{j k} \\
& +\sum_{k}^{K} \sum_{m}^{M} \sum_{n}^{N} z_{k m}^{n} e_{k m}^{n} l_{k m}=E-b^{+}+b^{-}
\end{aligned}
$$

The objective function (12) is together with constraint sets (3)-(8). The objective function equation (9) minimizes the model when the carbon is sold (or bought). Constraint (13) presents a certain quantity of the carbon is sold (or bought) when the carbon emission is less (greater) than $E \cdot p\left(b^{-}-b^{+}\right)$is the cost of the carbon trade.

\section{EMPRICAL STUDY}

An empirical study is conducted in this section to better understand how various carbon emission policies influence a major retailer's transportation cost and carbon emissions. Specifically, a chain supermarket of Beijing is used in this case study. Goods are collected on the Jing Xibei large logistics compounds, and then transferred to Ma Chi port logistics center; after col- 
MATEC Web of Conferences

Table 2. Vehicle types, transportation cost and carbon emission factor

\begin{tabular}{l|l|l|l|l}
\hline $\begin{array}{l}\text { vehicle } \\
\text { types }\end{array}$ & $\begin{array}{l}\text { maximum } \\
\text { capacity }(\mathrm{t})\end{array}$ & $\begin{array}{l}\text { unit transportation } \\
\operatorname{cost}(\mathrm{yuan} /(\mathrm{t} \bullet \mathrm{km}))\end{array}$ & $\begin{array}{l}\text { carbon emission fac- } \\
\text { tor }(\mathrm{kg} /(\mathrm{t} \bullet \mathrm{km}))\end{array}$ & $\begin{array}{l}\text { unit energyconsumption } \\
(\mathrm{L} /(\mathrm{t} \bullet \mathrm{km}))\end{array}$ \\
\hline $\mathrm{A}$ & 37 & 0.5 & 0.12 & 0.0678 \\
\hline $\mathrm{B}$ & 36 & 0.4 & 0.25 & 0.0692 \\
\hline $\mathrm{C}$ & 35 & 0.3 & 0.3 & 0.0606 \\
\hline
\end{tabular}

Table 3. Optimum solution of objective function under different carbon polices

\begin{tabular}{l|l|l|l|l}
\hline objective function & No carbon police & Carbon Tax & Carbon Cap & Carbon Trade \\
\hline distribution costsminimization & 11342 & 11546 & 11342 & 11429 \\
\hline Carbon emission $(\mathrm{kg})$ & 11342 & 11020 & 11342 & 11209 \\
\hline Carbon emission minimization $(\mathrm{kg})$ & 6107 & 6107 & 6107 & 6538 \\
\hline distribution costs & 19861 & 19983 & 19861 & 19734 \\
\hline
\end{tabular}

lection, they are shipped to Qing He distribution center; through assembly and picking processing, they are then sent to 10 supermarkets nearby. The locations of logistics base, logistics center, distribution center and supermarkets are unchanged in the long term.

\subsection{Date collection}

The demand at each supermarket is calculated based on its type and location. Multiple modes of transportation vehicles can be used in each distribution center.Table1 shows the total month demand of each supermarket and the distance of supermarkets around the distribution center. Transport vehicle types are also considered. A, B, and C are respectively represented as the Light truck of gasoline, the Medium-sized truck of gasoline and the Light-duty diesel. Table 2 presents for each maximum capacity, unit transportation cost, carbon emission factor( $\mathrm{kg} \mathrm{CO}_{2}$ per unit shipped) and unit energy consumption of each vehicle. Here, we assume that the policy tax rate is adopted between 0.01 to 0.1 yuan $/ \mathrm{kgCO}_{2 \mathrm{eq}}$, the initial value is 0.06 , the carbon emissions cap is 12000 , and the trading price is about 0.05 yuan/ $\mathrm{kgCO}_{2}$. The solution uses Cplex to solve the problems and results are shown in Table 3.

Table 1. Month demand and distance of supermarkets

\begin{tabular}{l|l|l}
\hline supermarket & $\begin{array}{l}\text { month demand } \\
\text { (tons) }\end{array}$ & $\begin{array}{l}\text { distance around } \\
\text { the distribution } \\
\text { center }(\mathrm{km})\end{array}$ \\
\hline 1 & 110 & 28.8 \\
\hline 2 & 220 & 5.3 \\
\hline 3 & 132 & 23.4 \\
\hline 4 & 323 & 8.7 \\
\hline 5 & 82 & 17.3 \\
\hline 6 & 278 & 10.3 \\
\hline 7 & 254 & 7.2 \\
\hline 8 & 302 & 10.3 \\
\hline 9 & 236 & 18.8 \\
\hline 10 & 190 & 6.2 \\
\hline
\end{tabular}

Table 3 shows that the optimal solution is completely different when only consider the single goal. Policymakers decide to adopt different objective functions, such as the minimum logistics cost or carbon emissions minimum, and its corresponding level of logistics costs and carbon emissions is completely different. In the case of no carbon policy, when policymakers are in pursuit of economic interests for the purpose in order to minimize the logistics cost, they often ignored in the process of transport carbon emissions to the environment, the impact of the level of carbon emissions is higher. When friendly environment is regarded as the main target, the lower the carbon emissions is, the higher the logistics transportation cost is. Therefore, when faced a two-fold economic benefits and environmental pressure, policymakers need to trade-off between the two choices.

\subsection{Effects of different carbon policies on objective function}

Carbon policy is still immature in our country. Given that making profits as the first goal of most companies, this paper regards transportation costs as the primary goal when studies effects of different carbon policies on transportation costs and carbon emissions. Results and discussion based on the supermarkets are shown as follows:

(1) Effects of carbon tax on transportation costs and carbon emissions

Table 4 presents the results of transportation costs and carbon emissions based on different tax rates. Supermarkets can change cost and carbon emissions by choosing different transportation vehicles. It is easy to see that when the tax rate is less than $0.03 y u a n / \mathrm{kg}$, the carbon emissions may not be significantly reduced. When the carbon tax rate is increased from 0.03 to 0.1 yuan/ $\mathrm{kg}$, transportation costs are increased from 11492 to 11492 and then grown slightly, while carbon emissions have dropped substantially. This is mainly because when carbon tax is lower, the cost of carbon emissions is lower related to transportation cost. Supermarkets will give priority to transportation costs and pay a certain cost of carbon emissions. Only if the cost of carbon emissions is much higher related to transportation cost, they will replace the type of transport vehicle and seek methods to reduce emissions. The results show that carbon emission is significantly reduced and the transportation cost is slightly increased with the continuous increase of carbon tax. 
ICETA 2015

Table 4. Transportation costs and carbon emissions under different tax rates

\begin{tabular}{l|l|l|l|l|l|l|l}
\hline carbon tax rates & 0.01 & 0.03 & 0.05 & 0.06 & 0.07 & 0.08 & 0.10 \\
\hline transportation costs & 11387 & 11492 & 11546 & 11567 & 11589 & 11599 & 11614 \\
\hline carbon emissions $(\mathrm{kg})$ & 11233 & 11142 & 11020 & 10873 & 9645 & 8107 & 6983 \\
\hline
\end{tabular}

Table 5. Transportation costs and carbon emissions under different carbon cap

\begin{tabular}{l|l|l|l|l|l|l|l}
\hline carbon cap & 12000 & 11000 & 10000 & 9000 & 8000 & 7000 & 6000 \\
\hline transportation costs & 11342 & 11347 & 11367 & 11389 & 11402 & 11423 & 11457 \\
\hline carbon emissions(kg) & 11342 & 11000 & 10000 & 9000 & 8000 & 7000 & 6000 \\
\hline
\end{tabular}

Table 6. Transportation costs and carbon emissions based on different carbon trade policies

\begin{tabular}{|c|c|c|c|c|c|}
\hline $\begin{array}{l}\text { carbon } \\
\text { cap }(\mathrm{kg})\end{array}$ & trading price & $\mathrm{CO} 2$ to buy $(\mathrm{kg})$ & $\begin{array}{ll}\mathrm{CO} 2 & \text { to } \\
\text { sell }(\mathrm{kg}) & \\
\end{array}$ & transportation cost & $\begin{array}{l}\text { carbon emis- } \\
\operatorname{sion}(\mathrm{kg})\end{array}$ \\
\hline \multirow{2}{*}{11000} & 0.05 & 0 & 13 & 11345 & 10987 \\
\hline & 0.08 & 0 & 4017 & 11123 & 6983 \\
\hline \multirow{2}{*}{10000} & 0.05 & 0 & 0 & 11367 & 10000 \\
\hline & 0.08 & 0 & 3017 & 11352 & 6983 \\
\hline \multirow{2}{*}{9000} & 0.05 & 0 & 0 & 11389 & 9000 \\
\hline & 0.08 & 0 & 2017 & 11376 & 6983 \\
\hline \multirow{2}{*}{8000} & 0.05 & 0 & 0 & 11402 & 8000 \\
\hline & 0.08 & 0 & 1017 & 11394 & 6983 \\
\hline \multirow{2}{*}{7000} & 0.05 & 0 & 0 & 11423 & 7000 \\
\hline & 0.08 & 0 & 17 & 11411 & 6983 \\
\hline \multirow{2}{*}{6000} & 0.05 & 983 & 0 & 11457 & 6983 \\
\hline & 0.08 & 0 & 0 & 11435 & 6000 \\
\hline
\end{tabular}

Only high carbon tax can effectively drive supermarkets to reduce carbon emission. In other words, supermarkets may be sensitive to a high rate after the carbon tax policy is implemented.

(2) Effects of carbon cap on transportation costs and carbon emissions

Table 5 shows the results of transportation costs and carbon emissions based on different carbon cap. According to the mandatory carbon policy, carbon emissions must be considered and distribution must be stopped operating when carbon emissions ceiling is reached. Transportation costs and carbon emissions are the same with that of no carbon policy which is implemented when the carbon cap is larger than $11000 \mathrm{~kg}$, and carbon cap can't afford to constraint function. Transportation cost is decreased with the increase of carbon emissions limits when the carbon cap is lower than $11000 \mathrm{~kg}$. Compared Table 4 with Table 5, it can be found that transportation costs and carbon emissions based on carbon cap are lower than cost and emissions that based on carbon tax. This implies that governmental departments can provide reasonable carbon emissions limits when making carbon policies, so as to reduce carbon emissions without increasing the transportation cost significantly.

(3) Effects of carbon trade on transportation costs and carbon emissions

To provide distribution more flexibility, a carbon cap-and-trade policy with a carbon exchange market can be implemented. The impact of the carbon cap-and-trade policy heavily depends on how to allocate the cap and what the market price is. The carbon trading price and the carbon emission limits are main factors influencing the retailers' decision in the carbon trading market. The carbon price could fluctuate a lot and it is also different in different carbon trading places. The prices used in this paper are selected from Beijing Environment Exchange, the average trading price is 0.05 yuan and the highest is about 0.08 yuan. According to the given limit of carbon emissions, the lower the carbon trading price is, the larger amount of carbon emissions will be, and the transportation cost is on the decline with the increase of carbon trading price. This shows that the revenues from the carbon exchange can compensate the transportation cost to a certain extent. When the price is high enough $(\mathrm{p}=0.08)$, carbon emissions will not be changed with caps. However, when the price is low $(\mathrm{p}=0.05)$, carbon emissions are increased with the increase of caps. The results show that transportation costs and carbon emissions are mainly affected by carbon trading price not by carbon cap based on the carbon trade policy.

(4) Comparison of different carbon policies

The findings from the case study compare the three carbon policies regarding their effectiveness of reducing carbon emissions and impacts on the transportation cost. As predicted in the introduction, each policy has achieved the goal of reducing carbon emissions. 
Comparison of the three policies finds that the transportation cost is highest based on carbon tax policy. However, if we reduce carbon emissions, a high carbon tax must be imposed to achieve remarkable results.

For the carbon cap policy, when the carbon emission is below the cap, the minimum transportation cost is the operational objective because the excess carbon cap can't be sold, and most of supermarkets are without the consciousness of environmental protection. However, when carbon emission is higher than the cap, the type of transport vehicle will be changed to reduce carbon emissions. The effectiveness of the carbon cap policy mainly depends on the carbon emissions limits assigned to enterprise, and transportation cost is declined with the increase of the carbon emissions limit.

For the carbon trade policy, the carbon emission rights or revenues can be obtained by buying or selling a certain amount of carbon emissions to achieve the goal of carbon reduction with lower cost. But this policy is vulnerable to fluctuations by the trading price, and the small amplitude fluctuation of the trading price can lead to the change of the distribution center decision and produce different levels of carbon emissions.

By the comparison of transportation costs and carbon emissions based on different policies, we find that carbon tax and carbon trade policies are effective in the case that does not affect the normal operation of supermarkets. But certain risks based on each policy implementation must be considered, such as how to effectively determine the carbon tax and limit of carbon emissions and carbon trading price, and so on. Through the above analysis, conclusions are drawn as follows: The level of carbon emissions and transportation costs could be changed based on the difference of vehicle types in some extent. When the carbon tax and the trading price are lower, the cost of carbon emissions is smaller related to transportation cost, and carbon emissions can't be significantly reduced. Thus only by high carbon tax and carbon trading prices, carbon emissions could be effectively reduced without significantly increasing transportation cost. Based on the condition ofthe normal operation of enterprises, carbon tax and carbon trade policies are more effectively achieved targets of carbon reduction compared with the carbon cap policy.

\section{CONCLUSION AND FUTURE RESEARCH}

In this paper, we introduced a four-layer urban logistics distribution network problem with a carbon emission constraint and proposed optimizations models to better understand how various carbon emissions policies influence supermarkets' logistics operations. Three relevant models are proposed based on carbon policies: carbon emission tax, carbon cap, and carbon trade. The models can help policy makers to predict the impact of policies on overall emissions in the freight transportation sector. Urban logistics distribu- tion may be influenced by various factors based on low carbon policies, such as urban transportation, infrastructure, and enterprises alliance and so on. Our future work about the study of equilibrium between the logistics cost and the carbon emissions may be researched under the condition of joint distribution or cooperation. It will be interesting to design the models which include alliance cooperation in the overall carbon footprint study for logistics enterprises.

\section{ACKNOWLEDGEMENT}

This research report was partially supported by the NSFC with grant numbers 71231001, and Beijing Philosophy and Social Science Foundation with grant number13JDJGB048.

This research uses data from one supermarket in Beijing, and the authors thank the manager of the supermarket as well.

\section{REFERENCES}

[1] Athena Roumboutsos, Seraphim Kapros, Thierry Vanelslander. 2014. Green city logistics: Systems of Innovation to assess the potential of E-vehicles. Research in Transportation Business \& Management: 1-10.

[2] Diabat, A. \& Simichi-Levi, D. 2010. A carbon-capped supply chain network problem. In: IEEE International Conference on Industrial Engineering and Engineering Management: 523-527.

[3] Figliozzi, M.A. 2010.The impacts of congestion on commercial vehicle tour characteristics and costs. Transportation Research Part E, 46(4): 496-506.

[4] Guy Walker, Alastair Manson.2014.Telematics, urban freight logistics and low carbon road networks. Journal of Transport Geography, 37: 74-81.

[5] HuijieGao. \& Jianhua Yang. 2015. Research on Model of City Logistics Network and Effects of Different Carbon Policies. POMS 26th Annual Conference, May 8 11, 2015. Washington DC, USA.

[6] Jianhua Yang, JidongGuo. \& Shugang Ma. 2013. Low-carbon city logistics distribution network design with resource deployment. Journal of Cleaner Production: 1-6.

[7] K. M. R. Hoen T. Tan J. C. Fransoo G. J. van Houtum. 2014. Effect of carbon emission regulations on transport mode selection under stochastic demand. Flexible Services and Manufacturing Journal, 26: 170-195.

[8] Mingzhou Jin, Nelson A. 2013. Granda-Marulanda, Ian Down. The impact of carbon policies on supply chain design and logistics of a major retailer. Journal of Cleaner Production: 1-9.

[9] Saif Benjaafar, Yanzhi Li. \& Mark Daskin. 2013. Carbon Footprint and the Management of Supply Chains:Insights from Simple Models. Automation Science and Engineering, IEEE Transactions, 10 (1): 99-116. 
ICETA 2015

[10] Schoemaker, Allen, Huschebek \& Monigl. 2006. Quan-

tification of urban freight transport effects I.BESTUFS

Consortium. (2006. www.bestufs.net). 